This item was submitted to Loughborough's Research Repository by the author.

Items in Figshare are protected by copyright, with all rights reserved, unless otherwise indicated.

\title{
Exploring vendor capabilities in the cloud environment: A case study of Alibaba Cloud Computing
}

PLEASE CITE THE PUBLISHED VERSION

https://doi.org/10.1016/j.im.2018.07.008

\section{PUBLISHER}

(c) Elsevier

\section{VERSION}

AM (Accepted Manuscript)

\section{PUBLISHER STATEMENT}

This paper was accepted for publication in the journal Information and Management and the definitive published version is available at https://doi.org/10.1016/j.im.2018.07.008.

\section{LICENCE}

CC BY-NC-ND 4.0

\section{REPOSITORY RECORD}

Zhang, Gongtao, and Ravishankar Mayasandra-Nagaraja. 2018. "Exploring Vendor Capabilities in the Cloud Environment: A Case Study of Alibaba Cloud Computing". figshare. https://hdl.handle.net/2134/34162. 


\title{
Exploring vendor capabilities in the cloud environment: A case study of Alibaba Cloud Computing
}

\begin{abstract}
Cloud computing is being viewed as an effective enabler for enhanced operational efficiency and flexibility in competitive business environments. Despite the increased knowledge on cloud computing, very few studies have been conducted to explore vendors' capabilities for service development and delivery. This gap prevents us from developing a full understanding of the service provision process and the actions through which vendors develop cloud services and create value for clients. In this paper, we present an in-depth qualitative case study of Alibaba Cloud Computing, China’s biggest Infrastructure-as-a-Service (IaaS) vendor, and identify five important capabilities, namely, cloud platform development, cloud platform deployment, IaaS imitation, IaaS commercialization, and IaaS improvement. We suggest that these capabilities and the associated actions are central to vendors' adoption of cloud computing, acquisition of knowledge, and delivery and improvement of their cloud service provision. This paper contributes incrementally to the evolving scholarship on cloud computing and also offers useful guidelines for current and aspiring vendors.
\end{abstract}

Key words: Cloud computing, Qualitative case study, Vendors' capabilities, Infrastructure-as-a-service (IaaS) 


\section{Introduction}

Cloud computing is an emerging technology paradigm for computing resource provision through the Internet (Armbrust et al., 2010; Marston et al., 2011; Willcocks et al., 2014; Venters and Whitley, 2012). It is a "model for enabling ubiquitous, convenient, on-demand network access to a shared pool of configurable computing resources (e.g., networks, servers, storage, applications, and services) that can be rapidly provisioned and released with minimal management effort or service provider interaction” (Mell and Grance, 2011). Cloud computing and its pay-per-use pricing model makes it possible for organizations to source and access reliable IT services. Cloud computing solutions give organizations immediate access to hardware resources with limited upfront investment and low spend on ongoing maintenance (Marston et al., 2011). Therefore, cloud computing has been viewed as an effective enabler for enhancing operational efficiencies and improving agility (Battleson et al., 2015). The cloud computing market has grown rapidly and dramatically with Bain \& Company predicting global cloud IT market revenues to reach US\$ 390 billion in 2020 (Brinda and Heric, 2017).

Cloud computing scholarship thus far has focused on two main perspectives. First, a number of studies have been conducted from a technical perspective, focusing on issues such as security, virtualization, architecture and pricing models (e.g., Paquette et al., 2010). This stream of research implicitly assumes that technical excellence alone underpins the successful implementation of cloud computing solutions. Second, a large proportion of existing research has been studied from the clients' perspective. These studies have focused on the barriers and opportunities for clients, in terms of comparative advantage, cost efficiencies and core competencies. For example, Chen and Wu (2013) have identified switching costs, privacy issues and security concerns as the biggest barriers to the adoption of cloud services. Similarly, Bhattacherjee and Park (2013) have identified security concerns with current models and anticipated omnipresence and relative usefulness as key reasons for migration of client firms to the cloud infrastructure. Battleson et al. (2015) argue that cloud computing can accelerate the ability of an organization to achieve dynamic capabilities.

Despite the growing corpus of cloud computing literature, very few studies explore vendor capabilities for service development and delivery. The relationship between vendors and cloud services is treated as a "black box." Although studies presume that vendors may have developed capabilities when building their services (e.g., Marston et al., 2011), there is scarce in-depth empirical illustrations of what these capabilities are and the actions underpinning them. This gap prevents the development of a deeper understanding of the cloud service provision process and, in particular, how value is created and transferred from vendors to clients. Understanding vendors' capabilities in IT service provision is crucial because they ultimately determine the service quality and long-term successful client engagement (Levina and Ross, 2003; Feeny et al., 2005). Against this background, this paper addresses two research questions: (1) What are the key vendor capabilities for cloud services delivery? (2) What organizational actions underpin the key vendor capabilities? Theoretically, the paper draws from the literature on resource-based view (RBV) and dynamic capabilities. RBV of the firm offers a useful lens to explore the resources and capabilities that enable cloud service development and delivery. The dynamic capabilities theory helps examine the reconfiguration of vendors' resource bases that potentially contribute to a sustainable competitive advantage. The paper is based on an in-depth qualitative case study of Alibaba Cloud Computing (Aliyun), the biggest Infrastructure-as-a-Service (IaaS) vendor in China. The findings of the case study highlight 
several important vendor capabilities and illustrate the key actions that contribute to the development, delivery, and improvement of cloud services. The paper also offers insights into the development and evolution of dynamic capabilities in the cloud computing industry. The rest of the paper is organized as follows. First, we provide a brief review of the literature on RBV and dynamic capabilities, and its applicability to the cloud computing context. We then present our qualitative case study approach and analyze the Aliyun case. We conclude with a discussion of the theoretical and practical implications of the case.

\section{Literature review}

\subsection{Resource-based view}

The RBV suggests that a firm can be considered as a collection of resources and capabilities (Wernerfelt, 1984; Barney, 1991). Resources are the tangible and intangible assets, and capabilities refer to "the capacity to deploy resources to a desired end" (Amit and Schoemaker, 1993). A competitive advantage is only likely to be realized if a firm can deploy "unique" resources/capabilities, which are valuable, rare, inimitable and non-substitutable (VRIN) (Barney, 1991). VRIN characteristics have the potential to help companies to create and sustain competitive advantage and achieve a superior long-term performance (Barney, 1991; Wade and Hulland, 2004; Barney, 2001). RBV is widely adopted in information systems (IS) research. For example, Wade and Hulland (2004) created a taxonomy of eight distinct IS capabilities divided into three broad classes, namely, inside-out, outside-in and spanning. Research also suggests that IS resources are likely to affect firm performance only when they are deployed in a manner that creates unique complementarities with other firm resources (Ravichandran and Lertwongsatien, 2005). Complementarity of resources can also determine the commercialization outcomes of technology innovations (Teece, 1986; Rothaermel, 2001). Teece (1986) suggests that in the absence of complementary resources (e.g., excellent distribution facilities), technology innovations are unlikely to be successfully delivered. Complementary resources can also contribute to the sustainability of the competitive advantage created by technology innovations. Even if other firms are able to imitate the technology innovation, they may not be able to obtain competitive advantage from imitation alone because they may not have access to the necessary complementary resources (Rothaermel, 2001).

Recent studies on RBV have focused on exploring resource acquisition and development, particularly from a process perspective (Barney et al., 2011; Bingham and Eisenhardt, 2008). For example, Wernerfelt (2011) considers the processes that enable firms to acquire resources and argues that the current stock of resources of a firm creates asymmetries in the competition for new resources. Firms expand their resource portfolios by developing their existing stock of resources, and as different firms acquire different new resources, small initial heterogeneities are amplified over time (Wernerfelt, 2011). Maritan and Peteraf (2011) explore firms' heterogeneous resource positions that lie at the core of RBV. They identify two mechanisms, namely, resource acquisition in markets and internal resource accumulation, and suggest that taking a process perspective helps better understand resource-based competition, as firms compete over time by utilizing various bundles of complementary resources (Maritan and Peteraf, 2011). Sirmon et al. (2011) develop the notion of "resource orchestration," which focuses on managerial actions of structuring, bundling, and leveraging resources to acquire competitive advantages. In summary, these studies show that different contexts of firms greatly influence the processes of resource acquisition and development and that these processes will 
evolve over time (Combs et al., 2011; Hodgkinson et al., 2014). The evolution of processes also brings into sharp focus the dynamic capabilities required to sustain a competitive advantage.

\subsection{Dynamic capabilities}

The notion of dynamic capabilities is rooted in RBV and is defined as the ability of a firm to "integrate, build and reconfigure internal and external competences to address rapidly changing environments" (Teece et al., 1997). Capabilities are seen as being both ordinary and dynamic (Winter, 2003; Teece, 2014). Ordinary capabilities merely enable firms to efficiently perform activities in the core business functions such as operations, administration, and governance (Teece, 2014; Teece, 2012). Dynamic capabilities, in contrast, are seen as higher order capabilities that transform ordinary capabilities and the resource base of a firm (Winter, 2003; Collis, 1994; Teece, 2014). They determine "the speed at, and degree to which" firms' bundles of resources can be aligned and recombined to match the requirements and opportunities of a changing environment (Teece, 2014). Ambrosini et al. (2009) identify three levels of dynamic capabilities-incremental, renewing, and regenerative-and point to different types of dynamic capabilities such as new product development, new idea generation and new learning. Dynamic capabilities are seen as being embedded in organizational processes and routines that reconfigure resources in response to market changes (Teece, 2007; Augier and Teece, 2009). The evolution of dynamic capabilities is path dependent and is likely to be guided through incremental learning (Zollo and Winter, 2002; Bingham et al., 2015). In terms of the consequences of dynamic capabilities, Teece (2007) argues that there is a direct relationship between dynamic capabilities and competitive advantage, whereas Eisenhardt and Martin (2000) suggest that dynamic capabilities cannot on their own be a source of competitive advantage or produce superior firm performance. Despite these differing views, there is now a general consensus that with the deployment of dynamic capabilities, organizations are able to reconfigure their resources/capabilities to match market changes and consequently acquire some degree of competitive advantage in the market place (Teece, 2007; Teece et al., 1997). Considering vendors' capabilities in the cloud computing context, we suggest that they may have the ordinary capabilities to produce and sell a defined (and static) set of entities and services (Al-Aali and Teece, 2014). However, they may also need to possess the dynamic capabilities to augment their ordinary capabilities and reconfigure their resource bases, particularly in intensely competitive markets.

\subsection{Cloud computing and vendor capabilities}

Cloud computing solutions are seen as a relatively novel class of IT resources that are deployed to reduce innovation barriers (Marston et al., 2011), enhance focus on core competencies (Garrison et al., 2012) and lower operating costs (Armbrust et al., 2010). They enable organizations to quickly add or remove resources on-demand and achieve a better matching of resources to workload (Venters and Whitley, 2012). Recent studies have explored the resources and capabilities that influence the adoption of cloud services. For example, Garrison et al. (2012) show that, to benefit from cloud services, organizations need to develop and utilize their relational, technical and managerial capabilities. In a more recent study, they note that relational rather than the technical and managerial capabilities could be most influential in facilitating cloud success (Garrison et al., 2015). Since cloud computing enables IT resources to be scaled up and down on demand, it helps organizations to quickly (re)configure internal IT resources and respond to market dynamics (Battleson et al., 2015). These examples suggest that successful cloud adoption depend on the purposeful and creative deployment of internal IT capabilities. 
In contrast to the focus on client IT capabilities, studies on vendor capabilities are limited. Marston et al. (2011) suggest that vendors may have developed capabilities in the process of developing and offering cloud services. Some studies on vendor capabilities have been conducted in the broader IT outsourcing literature (e.g., Levina and Ross, 2003; Nevo and Kotlarsky, 2014). For instance, by examining large IT outsourcing vendors, Levina and Ross (2003) identified three operational capabilities, namely, client relationship management capability, methodology development and dissemination capability, and personnel development capability. These three capabilities are seen as mutually reinforcing, and influencing value creation and service delivery. In their study of crowdsourcing, Nevo and Kotlarsky (2014) emphasize the importance of architectural capability for developing successful and long-term engagements with clients. In general, these studies suggest that vendors must have strong architectural and design knowledge, routines, and methodologies and the capacity to collect client-related knowledge, all of which lead to effective software design, development and implementation. They also underscore the main point that vendors' capabilities determine the quality of IT service development and delivery and help clients achieve better value.

Most studies in the literature situate the technical origins of cloud computing in IT outsourcing (Willcocks et al., 2013; Willcocks et al., 2014). As one of the outsourcing solutions, Application Service Providers (ASPs) made it possible for IT services to be outsourced through the Internet (Kern et al., 2001). Since the advent of ASPs, improvements have been made to allow for better coordination of large-scale computing resources, particularly in an on-demand manner (Venters and Whitley, 2012). The transfer from individual PCs and private data-centers to large-scale external data centers over the Internet is at the core of the cloud computing phenomenon (Boss et al., 2007; Armbrust et al., 2010). The architecture of large-scale data centers provides new data structures, data storage, systems and programming models (Ghemawat et al., 2003; Chang et al., 2006). In this new technological context, vendors need to develop significant internal capabilities so that the technical features of cloud computing can be effectively deployed to foster the development and delivery of cloud-based services. In the next sections of the paper drawing on an in-depth qualitative case study of Alibaba Cloud Computing (Aliyun), the largest IaaS vendor in China, we address two questions: (1) What are the key vendor capabilities for cloud services delivery? (2) What organizational actions underpin the key vendor capabilities?

\section{Research methodology}

We adopted the interpretive qualitative case study approach, which helps investigate phenomena embedded in specific contexts (Eisenhardt and Graebner, 2007; Sandeep and Ravishankar, 2015). We applied two criteria for case selection. First, we looked for a case organization with relevant knowledge and experience of developing and delivering cloud services to firm-level clients. Second, we aimed to select a cloud services vendor organization highlighted recently in the business press for its strong capabilities to detect and respond quickly to market changes. Thus, we selected Aliyun, which is known as one of the most successful cloud service vendors in China. 


\subsection{Research context}

Aliyun, headquartered in the capital of Zhejiang Province in Eastern China, was established in September 2009 to coincide with Alibaba's 10th anniversary, and since then, it has become the largest public cloud vendor in China (Ong, 2012). It offers data-centric and cloud-based services to external small and medium business (SMB) clients and to internal divisions within the Alibaba Group. Literally, “yun” in Chinese means “cloud.” Unlike other Alibaba's famous divisions such as Taobao and Alipay, Aliyun has caught the attention of business press only recently.

Aliyun's cloud service development and delivery can be classified into three distinct periods. Broadly, from 2009 to 2010 Aliyun focused on developing its cloud platform. From 2011 to 2012, Aliyun invited a small number of prospective clients to participate in the service development processes. From 2013 onwards, Aliyun started collaborating extensively with several external clients. In 2009, the notion of cloud computing was still new, and the first challenge was to develop a good understanding of the technology. Inspired by the success of Amazon's AWS and Google's cloud platform, the senior managers of Aliyun felt that cloud computing should be data-centric and support online data operations. The cloud model of Aliyun was based on three essential characteristics, which resulted in a new design of computing paradigm compared to traditional models. First, resources were pooled to serve multiple clients, based on a multi-tenant design (see Marston et al., 2011). In other words, the same set of resources was utilized to serve multiple clients, removing duplications and ensuring location independence. Second, resources were dynamically assigned or reassigned in response to clients' demand. Third, the usage of resources was monitored and reported for all clients.

Since 2011, Aliyun started delivering its cloud services to the market. With solid value propositions, secure IaaS bundles and strong client support provision, Aliyun has attracted a large number of clients and expanded aggressively. By mid-2013, Aliyun had acquired a client base of over 600,000 and had become the largest IaaS vendor in China. Additionally, it also acquired companies such as HiChina, a leading provider of Internet infrastructure services. Aliyun was awarded the world's first gold certification of cloud security by the British Standards Institute (BSI, 2014), which has further enhanced its global reputation.

\subsection{Data collection}

We collected our data in three stages. We conducted 48 semi-structured interviews in total (see Appendix B). The first stage was between February and April 2013, during which we conducted eight telephone interviews with cloud computing industry insiders in China to better understand the market and formulate interview questions for the subsequent site visit. In the second stage, between June and August 2013, we visited the Aliyun headquarters in China and conducted 36 face-to-face interviews. Each interview was recorded with the consent of the informants and was subsequently transcribed for data analysis. The interview questions were tailored to each informant's role. By interviewing informants at different hierarchical levels, we were able to obtain a variety of views. We asked a number of open-ended questions about the strategy implementation, challenges encountered, and the relationship with the parent organization and clients. Informants were given the opportunity to express their own opinions, regarding the technical development and cloud service delivery processes of the company. Four follow-up interviews were arranged in the third stage, between November 2014 and January 2015. All the interviews were conducted in Mandarin and were translated into English by the first author. In all, the transcripts amounted to 425 pages. 
We also collected several documents including company magazines, sales leaflets, newsletters, internal journals, memos and archival reports. These documents helped us accurately place the key events in time and better understand some of the complex technical concepts mentioned during the interviews. In addition to the documents produced by Aliyun, we also collected a number of reviews and articles on Aliyun and its services in online newspapers and business magazines (please see Appendix C). They helped us obtain the view of other independent observers and better triangulate our empirical material.

\subsection{Data analysis}

We adopted the "temporal bracketing" (Langley, 1999) strategy to analyze cloud service development and delivery of Aliyun. Accordingly, we created a chronological timeline showing the focus, objectives, stages, and activities of cloud service development and delivery at Aliyun (see Figure 1). The stages detail how Aliyun obtained essential resources and developed important capabilities. We complemented the "temporal bracketing" strategy with a "narrative” strategy (Langley, 1999) and constructed a narrative that described events in each period. In the first period (2009-2010), Aliyun focused on developing a new cloud platform. In the second period (2011-2012), the focus was on developing and delivering cloud services. In the third period (2013-2015), the focus was to enhance its services and collaborate with external clients. 
Period 1: $2009-2010$

Focus: Cloud platform development

Aliyun's Objectives

1. To develop a comprehensive understanding of cloud computing standards

To design, test and implement a new cloud platform

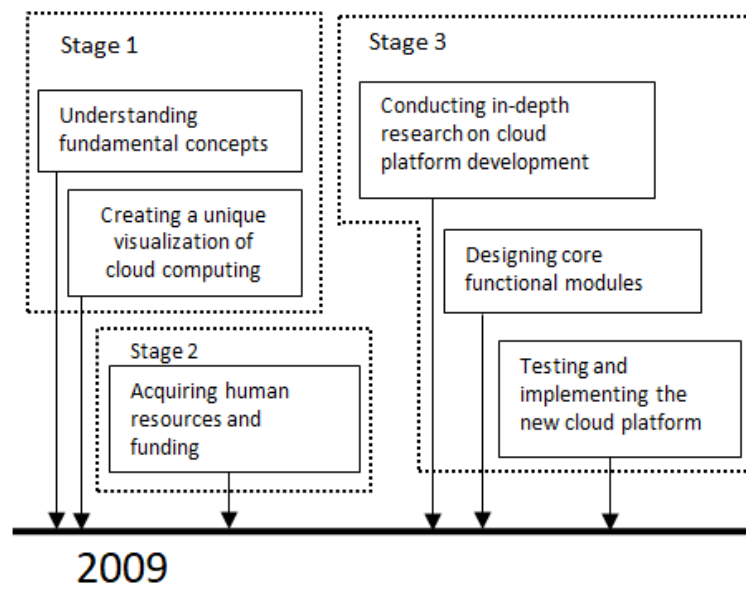

Stage 1: Understanding the standards

Stage 2: Resource acquisition

Stage 3: Cloud platform development
Period 2: 2011 - 2012

Focus: Cloud service development and delivery

\section{Aliyun's Objectives}

1. To design and develop a variety of laaS-based services

2. To improve cloud platform for service delivery

3. To successfully deliver services to the market

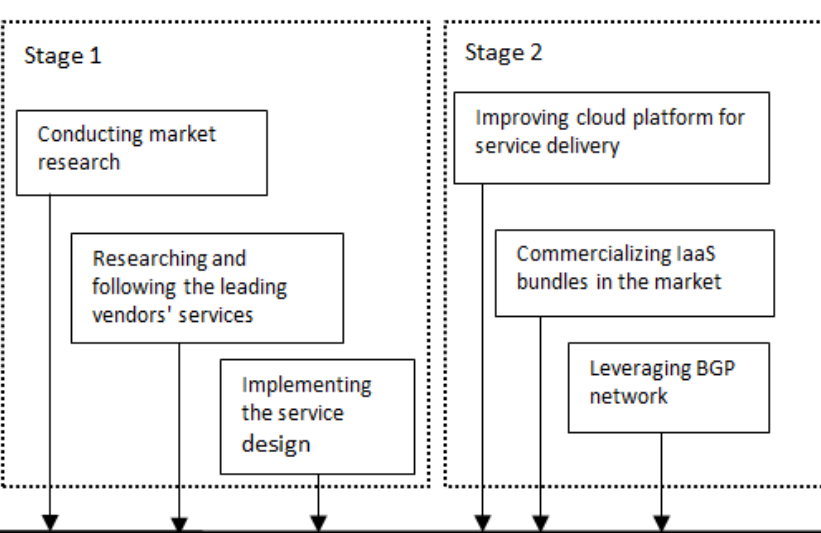

2011

Stage 1: Development of laaS bundles

Stage 2: Delivery of laaS bundles
Period 3: 2013-2015

Focus: Service improvement and stakeholder collaboration

Aliyun's Objectives

1. To improve service quality and service delivery

2. To build mutually beneficial relationships with externa stakeholders

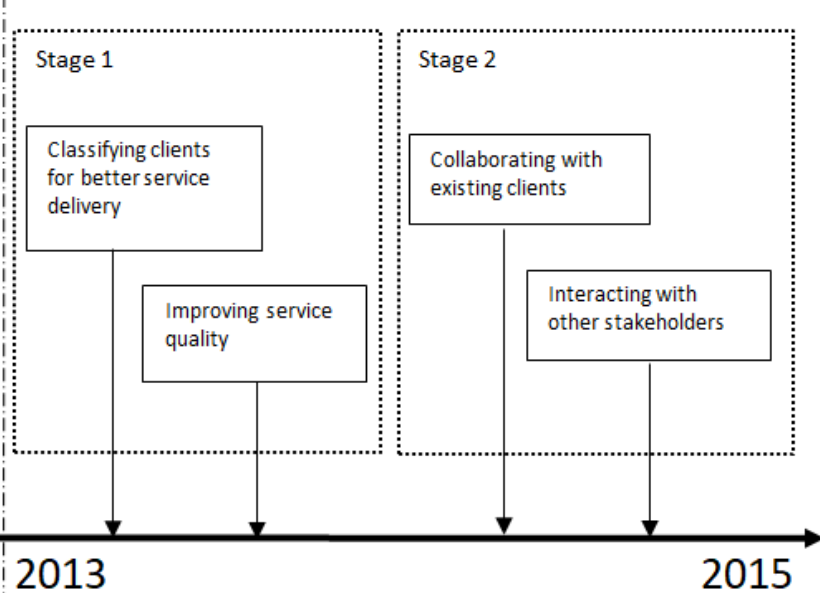

Stage 1: Improving service delivery and service quality Stage 2: Stakeholder collaboration

Figure 1: A timeline of key actions taken by Aliyun 
We adopted the "selective" coding method to identify central themes. From the data, we identified several first-order concepts across the three periods. From these first-order concepts, we then inductively moved to second-order theoretical categories. By examining the inter-linkages between first-order categories and second-order theoretical categories, we were able to develop an aggregated set of third-order theoretical dimensions (see Figure 2). During the coding process, we iteratively compared the emergent findings with recent cloud computing scholarship. Thus, respondents' explanations regarding designs, testing and improvement were abstracted as "cloud platform development." Their explanations regarding how they developed cloud architecture to utilize the cloud platform were labelled as "cloud platform deployment." When informants explained how they imitated market leaders' offerings to design and implement their own offerings, we connected this insight to the relevant literature on imitation (e.g., Lieberman and Asaba, 2006; Semadeni and Anderson, 2010; Chikofsky and Cross, 1990) and captured this finding through the label "IaaS imitation." Using a similar approach, we developed the aggregate theoretical dimensions of "IaaS commercialization" and "IaaS improvement.” 
- Identifying large-scale, low cost and standardization as three essential characteristics of cloud computing.

- Visualizing cloud services as basic utility services such as water, gas and electricity

- Deciding to develop a new cloud platform, with the support of senior managers

- Researching the literature on cloud platform development and using the insights to inform design activities.

- Implementing cloud platform using $\mathrm{C}++$

- Collaborating with other divisions inside the Alibaba Group to test the robustness and reliability of the cloud platform

Testing and implementing the cloud platform

- Developing the cloud architecture , learning from Google's and Amazon's architectures

- Using the cloud platform to underpin service development and delivery, and at the same time to underpin data operations of other divisions inside the Alibaba Group

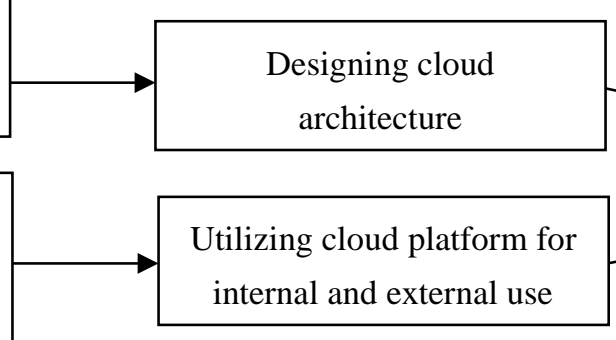

erstanding of cloud computing
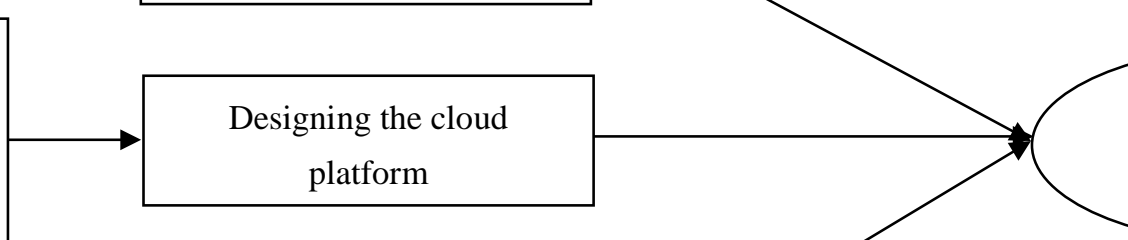

Cloud platform development

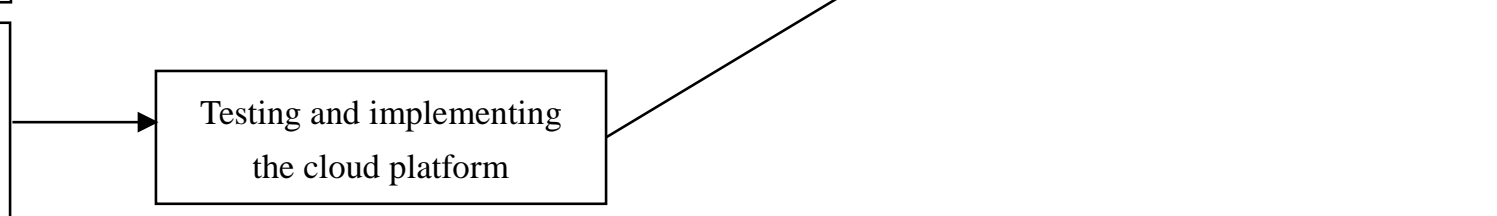

- Conducting market research to collect clients' requirements and concerns.

- Developing Data Loss Prevention policies to ensure secure data storage.

- Leveraging Border Gateway Protocol (BGP) network for better service delivery. 


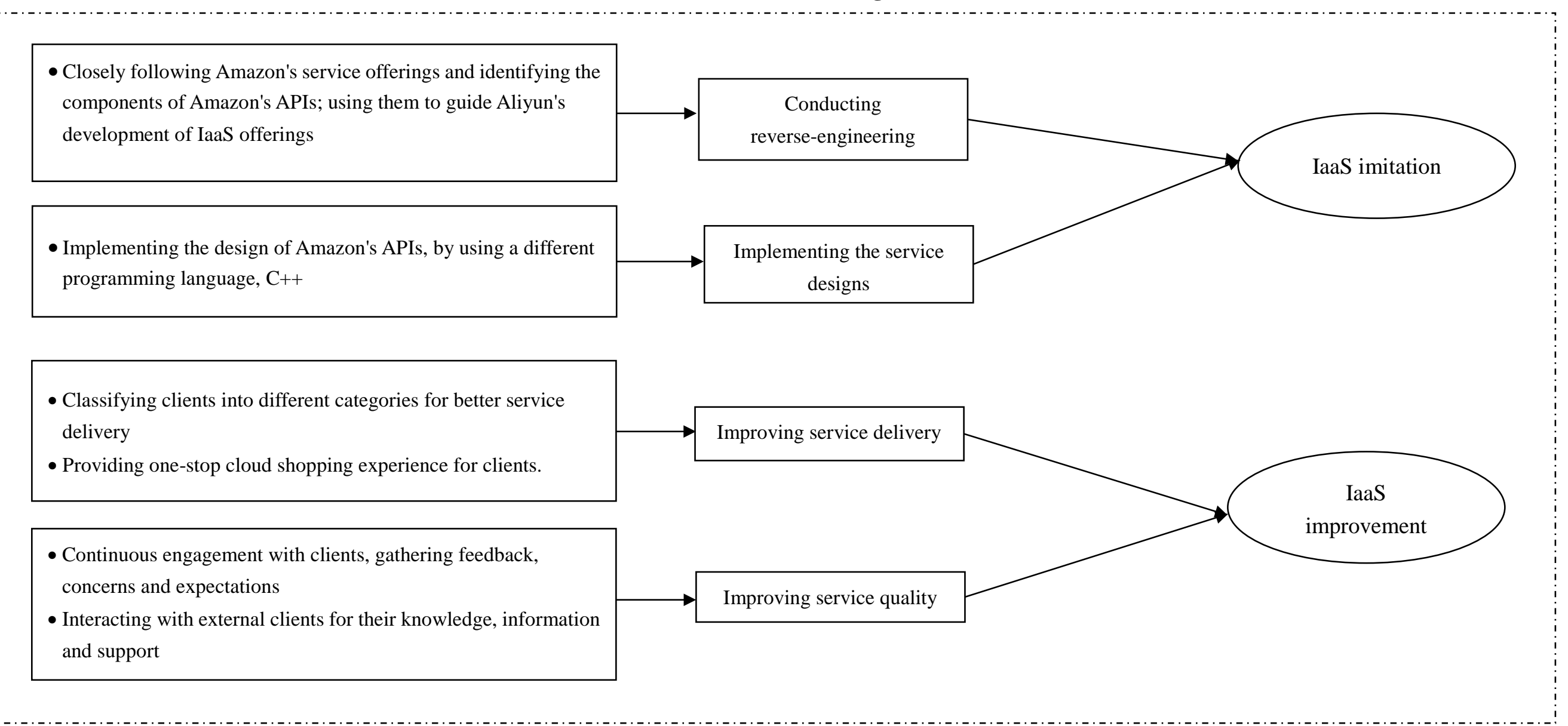

Figure 2: Data structure 


\section{Findings}

Across the three different time periods, we identified five capabilities that underpinned cloud service development and delivery of Aliyun (see Table 1). In the following subsections, we detail these capabilities and the actions underpinning them.

\begin{tabular}{|l|l|c|}
\hline \multicolumn{1}{|c|}{ Period } & \multicolumn{1}{c|}{ Capabilities identified } & Capability type \\
\hline Period 1: 2009-2010 & $\bullet$ Cloud platform development & Ordinary \\
\hline \multirow{2}{*}{ Period 2: 2011-2012 } & $\bullet$ Cloud platform deployment & Ordinary \\
& $\bullet$ IaaS commercialization & Ordinary \\
\cline { 2 - 3 } & $\bullet$ IaaS imitation & Dynamic \\
\hline Period 3: 2013-2015 & $\bullet$ IaaS improvement & Dynamic \\
\hline
\end{tabular}

Table 1: Capabilities across three periods

\subsection{Period 1: 2009-2010}

Aliyun visualized cloud services as a "basic utility service such as electricity, gas and water, which can be flexibly reconfigured by SMB clients" (Interviewee no. 30). Following such a visualization, large-scale data centers were built, and by recruiting a number of talented technical engineers, a new cloud platform was designed and implemented, initially for internal use. Next, Aliyun tested and improved the stability and robustness of the cloud platform to support huge volumes of online transactions.

\section{Cloud platform development}

IaaS vendors provide fundamental computing resources to clients (Mell and Grance, 2011), which are stored in large-scale data centers (Armbrust et al., 2010). Many informants stressed that it was crucial to possess a cloud platform to manage large-scale data centers. They saw the cloud platform as the entity "that managed the resource pool and data centers, supported data operations and guaranteed data security" (Interviewee no. 28). Aliyun spent over a year designing, testing and implementing its new cloud platform.

Drawing on the experience of Aliyun, we view "cloud platform development" capability as the ability of an IaaS vendor to design, test, implement, and improve its cloud platform (see Table 2). This capability is underpinned by a series of actions (Table 2, column 3), which includes formulating a detailed and reasonable strategic plan. A key dimension of this cloud development capability at Aliyun was the rigorous testing of the cloud platform, which further improved its robustness and reliability. Furthermore, the cloud platform evolved as "source codes of the cloud platform were iteratively rewritten to support more clients, more servers and more applications” (Interviewee no. 27). All informants noted that designing, implementing and improving the cloud platform was fundamental to offering IaaS services, without which it was not possible to interact with data centers and store and remove resources 
in response to clients' requests. Thus, we suggest that the "cloud platform development" capability is a key ordinary capability, as it determines whether vendors are able to offer elastic resource distribution, a basic dimension of cloud service delivery.

\begin{tabular}{|c|c|c|}
\hline Capability & Evidence from the case study & Actions \\
\hline $\begin{array}{l}\text { Cloud platform development } \\
\text { - The ability to design, test, } \\
\text { implement and improve cloud } \\
\text { platform }\end{array}$ & $\begin{array}{l}\text { "We designed and implemented a new } \\
\text { cloud platform, completely by ourselves. } \\
\text { As a big company with so many clients, } \\
\text { we don't want to be limited by third-party } \\
\text { platforms. For instance, if we used } \\
\text { Hadoop platform, we would not be able } \\
\text { to update our systems and applications } \\
\text { freely. Our future development may be } \\
\text { negatively influenced, and we cannot } \\
\text { take that risk." - Senior Software } \\
\text { Engineer A (Interviewee no. 14) }\end{array}$ & $\begin{array}{l}\text { - Developing an explicit and specific } \\
\text { interpretation of the technology } \\
\text { - Explicit detailing of the proposed } \\
\text { functions of the cloud platform } \\
\text { - Formulating a detailed and reasonable } \\
\text { plan for cloud platform development }\end{array}$ \\
\hline
\end{tabular}

Table 2: Cloud platform development capability

\subsection{Period 2: 2011-2012}

In this period, Aliyun performed a number of actions to facilitate service development and delivery. In developing its service offerings, Aliyun closely followed leading vendors' cloud architectures. Next, Aliyun improved its cloud platform and created unique selling points (USPs) for successful service delivery. Furthermore, Alibaba's Border Gateway Protocol (BGP) network and reputation were utilized to facilitate service delivery. We found three distinct capabilities at play during this period, namely, cloud platform deployment, IaaS commercialization, and IaaS imitation.

\section{Cloud platform deployment}

The cloud platform was deployed in the cloud architecture of Aliyun for both internal and external use. Informants explained that it was very unusual for an IaaS vendor to deploy its cloud platform like Aliyun. For instance, "Google deployed a cloud platform to support data storage and APIs for internal use, whereas Amazon offered public cloud services by renting Apache Hadoop” (Interviewee no. 23). In Aliyun, the cloud platform was deployed to underpin both Alibaba's internal data operations and, at the same time, to respond to external clients' requests. Informants reported that the cloud platform enabled Aliyun to quickly deploy resources in response to requests from some internal users. Soon, other internal divisions heard about the performance of the cloud platform and agreed to move their data to Aliyun's cloud platform.

However, informants stressed that it was more difficult and complex to serve external clients, as they had little knowledge of cloud computing technology and employed only a small number of IT technicians. Therefore, Aliyun created Internet-based self-service interfaces that were easy for clients to use and allowed them to independently purchase and configure resources through the Aliyun resource pool. The interfaces provided multitenant access to 
Aliyun's data centers. "Otherwise, clients' requests could not be processed by the cloud platform, and clients would not be able to access the resources in our data centres" (Interviewee no. 28).

The cloud platform was also utilized to support service delivery. In particular, the cloud platform was deployed to deal with various external requests outside the Alibaba network. Since a large number of clients were likely to send their resource requests concurrently, a robust and stable cloud platform, which enhanced the effectiveness and efficiency of resource distribution, was needed. Informants noted that the cloud platform was deployed to enable IaaS development and facilitate IaaS delivery. Senior software engineer A (Interviewee no. 14) commented

"We had a clear plan on how to deploy the cloud platform. Unlike some vendors who sell their cloud platform as an IS product, we decided to apply the platform to support service development and delivery. To facilitate the objective, we developed a cloud architecture where the platform can be fitted in."

The cloud platform deployment capability (see Table 3) enabled Aliyun to deploy resources swiftly in response to demand. The cloud platform was deployed to enable multi-tenant access to Aliyun's cloud and to Internet-based self-service interfaces. We suggest that this "cloud deployment" capability is an ordinary capability, as it makes it possible, at a basic level, for IaaS vendors to serve internal and external clients, and to concurrently deal with clients' resource requests.

\begin{tabular}{|c|c|c|}
\hline Capability & Evidence from the case study & Actions \\
\hline $\begin{array}{l}\text { Cloud platform deployment } \\
\text { - The ability to deploy the } \\
\text { cloud platform for IaaS } \\
\text { development and delivery }\end{array}$ & $\begin{array}{l}\text { "We had a clear plan on how to deploy the } \\
\text { cloud platform. Unlike some vendors who } \\
\text { sell their cloud platform as an IT product, } \\
\text { we decided to apply the platform to } \\
\text { support service development and delivery. } \\
\text { To facilitate our objectives, we developed a } \\
\text { cloud architecture where the platform can } \\
\text { be fittedin." - Senior software engineer A } \\
\text { (Interviewee no. 14) }\end{array}$ & $\begin{array}{l}\text { - Creating internet-based self-service } \\
\text { interfaces for clients } \\
\text { - Developing a cloud architecture for } \\
\text { cloud platform deployment }\end{array}$ \\
\hline
\end{tabular}

Table 3: Cloud platform deployment capability

\section{IaaS commercialization}

The commercialization approach of Aliyun consisted of three major organizational actions, namely, market research, cloud platform improvement and creation of USPs. First, extensive market research helped Aliyun understand clients' requirements, concerns and expectations. Second, the stability and security of the platform were improved with the inputs and support of key clients. Third, Aliyun created two USPs, namely, "no data loss" and "stable online services.” These USPs helped Aliyun develop strong value propositions. Marketing manager A (Interviewee no. 31) noted 
"As an IaaS vendor, we learned how to commercialize our services. We also learned to understand clients' requirements, concerns and expectations, and thereby to create solid value propositions to attract them. Alibaba's reputation did attract many clients. However, the service quality determines whether clients will eventually stay with us. Since cloud services were very new to the market, we taught and guided our clients to help them effectively use our services."

Aliyun also provided 24/7 support as well as considerate and friendly payment plans to reassure clients. Multiple IaaS solutions were implemented to meet clients' needs in different application scenarios. In line with Data Loss Prevention policies of Aliyun, clients' data were protected by a firewall and security suite, and each piece of data was maintained with three backup copies: "We guarantee that client data is safe. This is the most fundamental and important requirement. Otherwise, our services wouldn't be reliable at all." (Interviewee no. 16, Senior Software Engineer C).

We suggest that this "IaaS commercialization capability" (see Table 4) is an important, albeit ordinary, capability that involves fundamental activities such as market research and the creation of value propositions. Without this commercialization capability, IaaS vendors may not be able to acknowledge clients' requirements and concerns, and offer support. Without clear value propositions, IaaS bundles would struggle to attract clients and their delivery is unlikely to be successful.

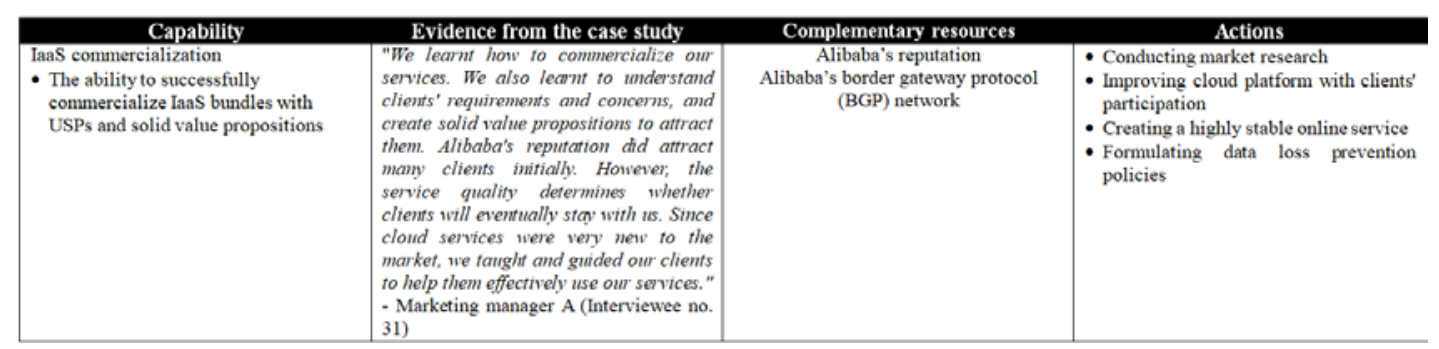

Table 4: IaaS commercialization capability

The broader literature suggests that complementary resources facilitate technology commercialization and that successful commercialization depends on availability of complementary assets (Teece, 1986; Rothaermel, 2001). In the case of Aliyun, two complementary resources facilitated the commercialization of IaaS, namely, the reputation enjoyed by the Alibaba group and its border gateway protocol (BGP) network. Alibaba's reputation enabled Aliyun to test and improve its cloud platform with the involvement of external clients while the BGP network facilitated seamless commercialization of Aliyun's IaaS. Owing to ongoing compatibility and broadband connectivity issues in China, some clients were unable to effectively access the IaaS bundles. Alibaba's BGP network deployed 
by Aliyun improved access speed for clients. Business analyst B (Interviewee no. 18) commented:

"We are the only vendor which has the BGP network and we can support any network operator in China. Based on our BGP, we can provide better cloud service performance. When clients use different broadband networks, they still access our services. This is also one very significant reason why many clients choose our services.”

\section{IaaS imitation}

Aliyun closely followed Amazon's service design. Informants explained that they undertook a detailed study of Amazon's whitepapers, books and online technical instructions, and thereby developed an excellent understanding of Amazon's IaaS bundles. In other words, crucial knowledge of technical components including system structures, APIs and algorithms was gained, and these components were then implemented based on Aliyun's cloud platform. For instance, Amazon's APIs were Java based, and those APIs defined the object behaviors, mediated by a set of class methods. Aliyun implemented the identified object behaviors based on its platform, by applying $\mathrm{C}++$, a different object-oriented programming language. Informants explained that they identified key components of Amazon's IaaS and their inter-relationships and this knowledge was used to facilitate the service design and implementation of Aliyun. Such an effort resonated with the notion of reverse-engineering, which refers to identifying a system's components and their inter-relationships and creating representations of the system in another form or at a higher level of abstraction (Chikofsky and Cross, 1990). Aliyun's imitation was “information-based” (Lieberman and Asaba, 2006) in the sense that as a late mover, Aliyun followed the market leader for superior information and knowledge. Our informants also explained that internal collective discussions, API prototyping, testing and extensive documentation were the key learning mechanisms that enabled them to acquire knowledge of Amazon's IaaS offerings and subsequently leverage such knowledge for cloud service development. Additionally, Aliyun closely tracked Amazon's service updates, which made it possible for the internal knowledge base to be reconfigured for new service development. In other words, Aliyun's imitation took into account new released updates of market leaders. This creative imitation approach enabled Aliyun to dynamically acquire superior knowledge and information about service development.

Significantly, the "imitation" dimension of the service development of Aliyun was restricted to the technical elements of the IaaS offerings. Informants explained that imitating Amazon's offerings was not sufficient to lead to successful service implementation because the Chinese market's specific requirements had to be factored in. Thus, Aliyun adopted a highly contextualized approach to shape its IaaS offerings before the official release. The firm created channels to encourage clients' participation in free trials, discussed acquired clients' 
feedback with the development team and refined key features and functionalities of their IaaS offerings to match local market requirements. Product manager B noted (Interviewee no. 23)

“We developed our IaaS offerings by closely following Amazon's bundles. But we didn't know whether our clients would like them. Therefore, we needed to find out, what they thought about our IaaS and how we may incrementally change our IaaS based on their feedback. Some features and functionalities had to be refined according to their requirements."

\begin{tabular}{|c|c|c|c|}
\hline Capability & Evidence from the case study & Main dynamic process & Actions \\
\hline $\begin{array}{l}\text { IaaS imitation } \\
\text { - The ability to reproduce } \\
\text { market leaders' IaaS bundles, } \\
\text { in order to facilitate service } \\
\text { development }\end{array}$ & $\begin{array}{l}\text { "By researching Amazon's technical } \\
\text { publications, we understood how their } \\
\text { services help clients acquire benefits and } \\
\text { why clients found the services useful. We } \\
\text { obviously only had access to publicly } \\
\text { available information such as Amazon's } \\
\text { API descriptions and not to explicit } \\
\text { technical details. But based on such limited } \\
\text { technical information, we were able to } \\
\text { thoroughly examine their service by } \\
\text { studying APIs, and we were able to } \\
\text { implement similar entities. For example, } \\
\text { we could identify the object behaviours } \\
\text { defined by Amazon's APIs. We implemented } \\
\text { those object behaviours by using C++, } \\
\text { based on our platform. We then need to } \\
\text { further improve the new implemented APIs } \\
\text { for better performance... The process was } \\
\text { continuous and long-term, and very } \\
\text { important to our innovation." - Product } \\
\text { Manager B (Interviewee no. 23) }\end{array}$ & $\begin{array}{l}\text { Learning (Teece et al., 1997; Zollo } \\
\text { and Winter, 2002): } \\
\text { Aliyun routinely updated its } \\
\text { services, based on the knowledge } \\
\text { obtained by reverse engineering } \\
\text { technical components of Amazon's } \\
\text { IaaS. }\end{array}$ & $\begin{array}{l}\text { - Researching market leaders' technical } \\
\text { publications including whitepapers, } \\
\text { books and online technical } \\
\text { instructions } \\
\text { - Examining market leaders' IaaS } \\
\text { bundles } \\
\text { - Identifying technical components of } \\
\text { leaders' IaaS by reverse-engineering } \\
\text { - Designing similar technical } \\
\text { components based on internal cloud } \\
\text { platform. } \\
\text { - Implementing the design of technical } \\
\text { components }\end{array}$ \\
\hline
\end{tabular}

Table 5: IaaS imitation capability

We therefore suggest that the "IaaS imitation capability" is the ability to reproduce market leaders' IaaS bundles to facilitate service development (see Table 5). The capability helps the IaaS vendor respond to technological changes in the market by tracking market leaders' service updates. Since market leaders constantly deliver new updates of their services, imitators may track leaders' updates in a dynamic and progressive manner and through reverse engineering routines reconfigure their own resource and knowledge bases. As noted above, Aliyun reconfigured its knowledge base for new service bundles and applications by following Amazon's updates. The company also reconfigured and enhanced its resource base by recruiting skilled engineers to ensure the effective use of new obtained knowledge for service development. IaaS imitation capability may thus be seen as a dynamic capability, which involves responding to leading vendors' service updates and reconfiguring the internal resource and knowledge bases to facilitate IaaS development. Product manager A (Interviewee no. 22) commented:

"As Amazon is still the pioneer in the global market, we keep track of its IaaS bundles and solutions. We consider such action as the major source for our innovation, and we can thus keep unnecessary additional investments to a minimum. Furthermore, by learning from and translating their services and applications to meet the needs of the China market, we can deliver new services.” 
The dynamic capability literature suggests that the "learning” process is rooted in knowledge articulation and codification (Zollo and Winter, 2002). In line with this literature, we found at Aliyun that a general articulation of knowledge was necessary, but not sufficient, as the processes of evaluating, implementing and testing new APIs and algorithms are complex and require a serious breadth and depth of technical knowledge. Here, knowledge codification served as a crucial supporting mechanism to simplify processes governing the local development of new technical components. For instance, Aliyun developed several manuals (please see Appendix C) to facilitate the processes of developing and testing new APIs based on its cloud platform. Further, the well-developed cloud platform also served as a complementary resource that facilitated successful imitation efforts, by providing a formidable base for the development, testing and storing of technical components.

\subsection{Period 3: 2013-2015}

In this period, Aliyun focused on improving its IaaS offerings by interacting extensively with external clients. To facilitate service improvement, Aliyun enacted two key actions. First, clients were classified into different categories, and thereby, customized applications and solutions were provided to each category. Second, Aliyun improved its service bundles for better service quality by regularly tracking clients' feedback.

\section{IaaS improvement}

We suggest that "IaaS improvement capability" is the key ability of an IaaS vendor to improve service quality and service delivery, thus creating better value (see Table 6). As reported by informants, clients might "change their requirements for better service quality and service delivery, more functionality or cheaper prices" (Interviewee no. 33). Furthermore, clients have "evolving expectations of Aliyun's services, with their growing experience of using the selected offerings" (Interviewee no. 34). The capability can therefore be seen as dynamic, as it involves the delivery of incremental service improvements in response to clients' changing requirements and evolving expectations. The capability is bolstered by significant learning through "telephone interviews, on-site visits and online questionnaires” (Interviewee no. 23) to explore clients' evolving and varying expectations. Aliyun classified its clients into different industry categories such as "E-commerce Cloud," "Finance Cloud," and "Game Cloud" and offered customized solutions and applications to each category:

"In the online game industry, clients require large volumes of data capacity to store millions of players' information. But, in the online retailing market, clients ask for elastic and highly scalable data storage rather than capacity. Clients have similar requirements only if they are in the same industry.” (Interviewee no. 33). 
Software engineer D (Interviewee no. 13) noted

"I think our innovation is continuous, non-stop, and long-term. By interacting with clients, we keep tracking their requirement and exploring their expectations. More importantly, we aim to provide further innovative and more acceptable services. The process is endless for sure."

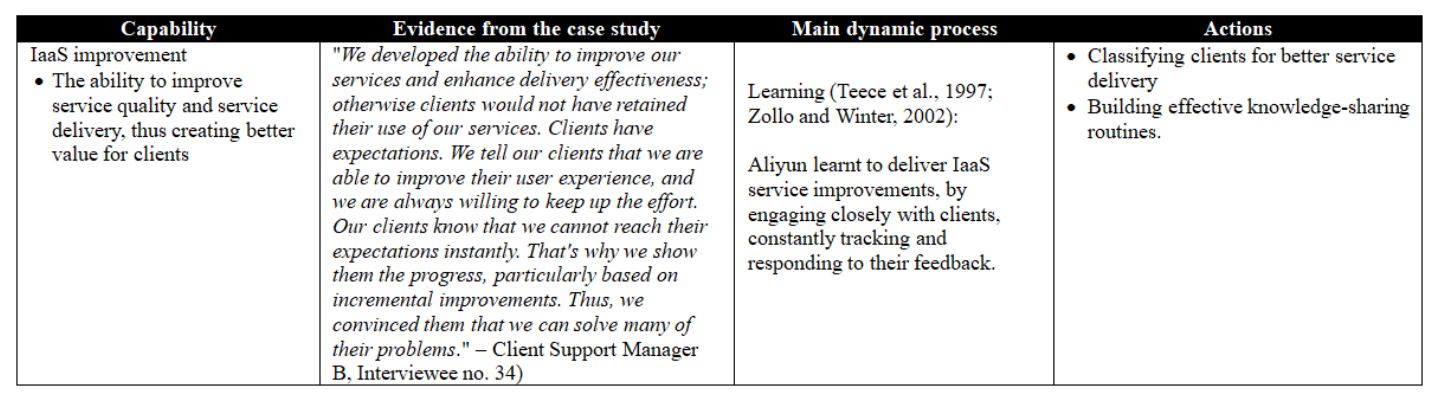

Table 6: IaaS improvement capability

Aliyun's engaged in key "knowledge sharing routines" (Dyer and Singh, 1998) through regular interactions with clients and paying close attention to client feedback, which helped renew the knowledge base of the company. In other words, these actions also included what Teece et al. (1997) referred to as "repetition and experimentation"-continuous client interaction and the testing of new service or application prototypes for service improvements. Thus, Aliyun's IaaS bundles kept evolving in response to the changing needs of their clients and remained competitive and valuable in the market. Client support manager A (Interviewee no. 33) noted

"Interacting with clients is essential and very necessary for us to deliver improvements and foster innovation. The interaction is on-going and continuous. ... We hope that our clients can provide more feedback, and therefore we can improve our services. Similarly, our clients hope that we can deliver improvements to match their requirements. For us, it is important to balance between what we can improve and what clients require."

\section{Discussion}

Thus far, vendors' capabilities and underpinning actions have not been systematically examined in cloud computing studies. Against this backdrop, our case study has highlighted the ordinary and dynamic vendor capabilities at play in cloud service development and delivery. The findings above provide several insights into a portfolio of IaaS vendors' capabilities, which includes cloud platform development, cloud platform deployment, IaaS commercialization, IaaS imitation, and IaaS improvement.

First, they suggest that IaaS vendors may move into the cloud technology context with two capabilities, namely, platform development and platform deployment. The cloud platform 
development capability and the corresponding actions enable vendors to deploy resources and manage large-scale data centers. The cloud platform deployment capability enables the effective utilization of the cloud platform for IaaS development and delivery. Second, the findings complement the existing literature by showing the actions through which an IaaS vendor may develop commercialization capability for effective service delivery. In particular, the study corroborates early research on innovation commercialization (e.g., Teece, 1986) showing how complementary assets play an important role in IaaS delivery. Third, the findings show how cloud services can be developed through a series of creative actions leading to what we have termed as IaaS imitation capabilities. In the existing literature, imitation is typically classified into two types, namely, strategic-level and offering-level imitations. Strategic-level imitation is not easily enacted and more likely to fail owing to multiple reasons such as causal ambiguity, complexity and tacit knowledge issues (Lieberman and Asaba, 2006; Bingham and Eisenhardt, 2008). By contrast, offering-level imitations are easier to enact and help mimic a market leader or reproduce a pioneer's products/services in existing technologies, designs and functions (Luo et al., 2011; Posen et al., 2013). As seen with Aliyun, such offering-level imitations can help vendors to find inspiration from market leaders' and to deliver customized services. These attributes of vendors' imitation capability are consistent with similar observations in recent studies on imitation (Semadeni and Anderson, 2010; Lieberman and Asaba, 2006; Luo et al., 2011). As we have emphasized above, this type of imitation is likely to be a dynamic capability in the cloud computing context, incorporating effective reverse-engineering routines and learning mechanisms that effectively translate the acquired explicit knowledge through imitation into the local context. While imitation more often than not gets bad press, incumbents need to show tremendous intelligence and develop complex operations to translate the innovation they seek to imitate into their particular markets. It is important to recognize that success in such an endeavor will depend on access to a qualified talent pool. In this sense, this study hints at the top-notch IT talent available in China and to their ability to learn fast. Finally, the study illustrates IaaS vendors' actions that lead to improvement capabilities. Such improvement capabilities are dynamic in nature, as it involves ongoing interactions with clients and effective knowledge sharing routines.

\subsection{Contribution to research}

In recent years, debates on cloud computing have focused on two areas-the technical aspects of cloud computing and clients' engagement with cloud computing. However, the cloud vendors' perspective has rarely been explored, and the relationship between vendors and cloud computing has been treated as a "black box." Although some research (e.g., Marston et al., 2011) has hinted that vendors might have developed capabilities when building their services, vendor capabilities have not been the explicit focus of prior studies. Against this backdrop, the study has identified key vendor capabilities for cloud service 
development and delivery. It has also highlighted the crucial organizational actions that contribute to the creation and nurturing of vendor capabilities in the cloud computing environment. Based on our findings, we would argue that it is the effective development of vendors' capabilities and not just technical excellence that explains how value is created and transferred from cloud vendors to clients. In recent years, many cloud vendor firms have proliferated globally. A proportion of them may possess only ordinary capabilities and hence may not be able to sustain and scale their operations. Our study throws light on the kinds of dynamic capabilities and the underlying actions that might help cloud computing vendors sustain a competitive advantage. Conceptually, we may think of four overlapping phases of the vendor's cloud computing journey, within which both ordinary and dynamic capabilities are orchestrated (see Table 7).

\begin{tabular}{|c|c|c|}
\hline Phases & Capabilities & Capabilities in action \\
\hline Adoption & $\begin{array}{l}\text { - Cloud platform } \\
\text { development (ordinary) } \\
\text { - Cloud platform } \\
\text { deployment (ordinary) }\end{array}$ & $\begin{array}{l}\text { - Moving to the cloud computing } \\
\text { context } \\
\text { - Ensuring the effective use and } \\
\text { management of large-scale data } \\
\text { centers } \\
\text { - Developing solutions for successful } \\
\text { cloud platform deployment }\end{array}$ \\
\hline $\begin{array}{l}\text { Deep knowledge } \\
\text { acquisition }\end{array}$ & - IaaS imitation (dynamic) & $\begin{array}{l}\text { - Obtaining superior knowledge for } \\
\text { service development } \\
\text { - Tracking market leaders and } \\
\text { translating APIs of market leaders' } \\
\text { IaaS offerings into the local context }\end{array}$ \\
\hline Delivery & $\begin{array}{l}\text { - IaaS commercialization } \\
\text { (ordinary) }\end{array}$ & $\begin{array}{l}\text { - Ensuring service delivery to the } \\
\text { targeted market } \\
\text { - Facilitating service delivery with } \\
\text { complementary resources }\end{array}$ \\
\hline $\begin{array}{l}\text { Service } \\
\text { improvement }\end{array}$ & $\begin{array}{l}\text { - IaaS improvement } \\
\text { (dynamic) }\end{array}$ & $\begin{array}{l}\text { - Gathering clients' feedback } \\
\text { - Delivering improvements in service } \\
\text { offerings and quality }\end{array}$ \\
\hline
\end{tabular}

Table 7: The four phases of vendors' cloud computing journey

In the adoption phase, vendors develop the ability to develop a cloud platform and to deploy the platform for service development and delivery. These capabilities are built on the effective management of data centers and a positive engagement with client requests. In the deep knowledge acquisition phase, vendors' imitation capabilities help them obtain superior and explicit knowledge from market leaders. They may regularly follow market leaders' technical updates and dynamically reconfigure their own resource and knowledge bases. During the delivery phase, vendors may draw on crucial complementary resources to 
effectively commercialize their services. The service improvement phase may determine whether and to what extent clients continue with a given vendor service. This phase is characterized by vendors' ability to improve their services following feedback from clients.

This study adds to recent literature regarding the effects of context conditions on dynamic capabilities. The Chinese information technology (IT) market is fluid, language-sensitive and fast moving (Williamson, 2016). In this context, both the technical landscape and the clients' requirements are evolving rapidly. These unique characteristics of the Chinese market underpin vendor companies' focus on efficient reverse-engineering and knowledge-sharing routines for service development and improvement. Such routines can help in the development of dynamic capabilities such as IaaS imitation and IaaS improvement for sensing innovation opportunities and changing market needs. Thus, we would suggest that unique local contextual conditions, rather than conventional global wisdom about dynamic capabilities have a greater influence on whether a particular capability (e.g., IaaS imitation) is rendered dynamic or not. Further, our study shows how actions of imitation and improvement, which at first glance may appear quite plain, in fact turn out to be dynamic capabilities that provide a distinctive competitive advantage for cloud service providers. How do these capabilities turn out to be so valuable for cloud computing vendors? One possible explanation is that while a number of vendors keen to jump on the "cloud" bandwagon enter a given cloud computing market, few can proactively deliver new and innovative services as well as consistently improve on their existing services. If an industry has clear global market leaders, as cloud computing does, then incumbents in big emerging markets (e.g., China and India) may be able to take inspiration from the market leaders and imitate and improve their way to a sustainable competitive advantage. However, as seen with our Aliyun case, such success is impossible to achieve without excellent knowledge of the target market segments. From the perspective of global market leaders in cloud computing, new and emerging markets could demand the orchestration of a different set of dynamic capabilities. New evaluation processes, including local knowledge articulation and codification, may need to be developed to deliver competitive cloud service delivery.

\subsection{Practical implications}

Our study has some key implications for current and aspiring vendors regarding the development and delivery of cloud services. First, the Aliyun experience suggests that rather than simply following generic cloud computing standards, vendors may be better off developing innovative solutions in their adoption of large-scale data centers. For example, they could conduct incremental development of a rented cloud platform to respond to client requests if they do not currently possess the resources and the technical capability to develop a completely new platform from scratch. Second, vendors may be able to facilitate cloud service development by closely following market leaders' offerings and updates. Such 
imitation efforts can be particularly helpful to vendors in emerging markets, as they can acquire superior knowledge and information from market leaders. Our findings have illustrated how such an imitation can unfold in practice and how newly acquired knowledge can be applied in cloud service development. These insights can help vendors create efficient and cost-effective reverse-engineering routines and learning processes, which in turn may enable them to translate offering-level imitations into competitive innovations. However, these insights do not suggest that vendors can simply replicate market leaders' offerings. Taking inspiration from the offerings of market leaders may be an important first step, but it is not sufficient to ensure successful cloud service development and delivery. Vendors need to carefully consider how best to adapt the features of leaders' offerings to their current service portfolios. Thus, existing services may evolve for new features, and at the same time, new service offerings may be created within the current portfolio.

Third, managers may use Aliyun's experience as a guide to evaluate and manage their own actions during the process of service delivery. Cloud service improvement is crucial, as it determines whether clients will retain their use of current services. Cloud services are on-demand (Armbrust et al., 2010) and clients can stop their use at any time. Managers need to proactively and regularly interact with clients and keep them informed of service improvements so that they may continue using current services. Finally, managers need to carefully close the gap between the perceived value of service improvements delivered by tracking market leaders' updates and their actual value as captured in client feedback.

\subsection{Limitations and future research}

This paper has several limitations. First, the primary research underlying the paper is based on a single case and therefore caution must be exercised in generalizing to other contexts. The findings may be particularly applicable to institutional settings similar to the one in which Aliyun operates. Second, the paper mainly focuses on the vendors' perspective of cloud service development and delivery, and Aliyun's clients' views were not elicited during the study. We admit that a fuller and more detailed view of a vendor's capabilities can be obtained through a detailed examination of how their clients perceive such capabilities. Third, the findings of our study may be less applicable to other types of cloud service providers (e.g., PaaS vendors) who may undertake a different set of unique actions for effective service development and delivery.

In terms of future research, we would suggest large-scale quantitative studies that examine both vendor and client capabilities for effective adoption of cloud services. Future research also needs to explore how cloud computing is applied in different emerging markets. In particular, such studies could focus on the increasing use of cloud-based services by SMB clients in emerging markets. Additionally, further research can be conducted to explore what 
particular capabilities are possessed by different categories of cloud vendors and how they evolve in response to new technologies, regulations and market demand.

\section{Concluding remarks}

In this paper, we have explored vendors' capabilities and actions for cloud service development and delivery. Drawing on the RBV of the firm and the notion of dynamic capabilities, we conducted an in-depth case study of Aliyun, the biggest IaaS vendor in China. The findings point to five crucial cloud vendors' capabilities, namely, cloud platform development, cloud platform deployment, IaaS commercialization, IaaS imitation and IaaS improvement. The findings also highlight how IaaS imitation and IaaS improvement can turn into key dynamic capabilities that help vendors deliver high-quality cloud services at scale and sustain a competitive advantage. Analytically, the findings suggest that both ordinary and dynamic capabilities are orchestrated in four overlapping phases of adoption, deep knowledge acquisition, delivery and service improvement. 


\section{Reference:}

Al-Aali, A. \& Teece, D. J. (2014). International Entrepreneurship and the Theory of the (Long-Lived) International Firm: A Capabilities Perspective. Entrepreneurship Theory and Practice 38 (1), 95-116.

Ambrosini, V., Bowman, C. \& Collier, N. (2009). Dynamic capabilities: An exploration of how firms renew their resource base. British Journal of Management 20 (1), 9-24.

Amit, R. \& Schoemaker, P. H. (1993). Strategic assets and organisational rent. Strategic Management Journal 14 (1), 33-46.

Armbrust, M., Fox, A., Griffith, R., Joseph, A., Katz, R., Konwinski, A., Lee, G., Patterson, D., Rabkin, A., A.Stoica, I. \& Zaharia, M. (2010). A View of Cloud Computing. Communications of the ACM April, 53 (4), 50 - 58.

Augier, M. \& Teece, D. J. (2009). Dynamic Capabilties and the Role of Managers in Business Strategy and Economic Performance. Organisation Science 20 (2), 420-421.

Barney, J. B. (1991). Firm resources and sustained competitive advantage. Journal of Management 17 (1), 99-120.

Barney, J. B. (2001). Is the Resource-Based "View" a Useful Perspective for Strategic Management Research? Yes. Academy of Management Review 26 (1), 41-56.

Barney, J. B., Ketchen Jr., D. \& Wright, M. (2011). The Future of Resource-Based Theory: Revitalization or Decline? Journal of Management 37 (5), 1299-1315.

Battleson, D. A., West, C. W., Jongwoo, K., Balasugramaniam, R. \& Robinson, P. S. (2015). Achieving dynamic capabilities with cloud computing: an empirical investigation. European Journal of Information Systems, 1-22.

Bhattacherjee, A. \& Park, S. C. (2013). Why end-users move to the cloud: a migration-theoretic analysis. European Journal of Information System March (1), 1-16.

Bingham, C. B. \& Eisenhardt, K. M. (2008). Position, Leverage and Opportunity: A Typology of Strategic Logics Linking Resources with Competitive Advantage. Managerial and Decision Economics 29, 241-256.

Bingham, C. B., Heimeriks, K., Schijven, M. \& Gates, S. (2015). Concurrent learning: how firms develop multiple dynamic capabilities in parallel Strategic Management Journal 36, 1802-1825.

Boss, G., Malladi, P., Quan, D., Legregni, L. \& Hall, H. (2007). Cloud Computing, IBM Technical Report: High Performance on Demand Solutions (HiPODS).

Brinda, M. \& Heric, M. (2017). The Changing Faces of the Cloud. Bain \& Company.

Bsi. (2014). Aliyun first to achieve CSA STAR Gold Certification [Online]. Available: http://www.bsigroup.com/en-GB/about-bsi/media-centre/press-releases/2014/January-2014/Al iyun-first-to-achieve-CSA-STAR-Gold-Certification/\#.VFqyEs60Prf [Accessed December 24th 2017].

Chang, F., Dean, J., Ghemawat, S., Hsieh, W. C., Wallach, D. A., Burrows, M., Chandra, T., Fikes, A., Gruber, R. E. \& Inc., G. (2006). Bigtable: A Distributed Storage System for Structured Data. In: OSDI '06 Proceedings of the 7th symposium on Operating systems design and implementation, November. 6-8, Seattle, WA, USA.

Chen, P. \& Wu, S. (2013). The Impact and Implications of On-Demand Services on Market Structure. Information System Research 24 (3), 750-767.

Chikofsky, E. \& Cross, J. I. (1990). Reverse engineering and design recovery: A taxonomy. IEEE 
Software 7 (1), 13-17.

Collis, D. J. (1994). How valuable are organisational capabilities? . Strategic Management Journal 15 (Winter Special Issue), 143-152.

Combs, J. G., Ketchen, J. D. J., Ireland, R. D. \& Webb, J. W. (2011). The Role of Resource Flexibility in Leveraging Strategic Resources. Journal of Management Studies 48 (5), 1098-1125.

Dyer, J. H. \& Singh, H. (1998). The relational view: cooperative strategy and sources of interorganisational competitive advantage. Academy of Management Review 23 (4), 660-679.

Eisenhardt, K. M. \& Graebner, M. E. (2007). Theory Building From Cases: Opportunities And Challenges. Academy of Management Journal 50 (1), 25-32.

Eisenhardt, K. M. \& Martin, J. A. (2000). Dynamic capabilities: what are they? . Strategic Management Journal 21, 1105 - 1121.

Feeny, D., Lacity, M. \& Willcocks, L. (2005). Taking the measure of outsourcing providers. Sloan Management Review 46 (3), 41 - 48.

Garrison, G., Kim, S. \& Wakefield, R. L. (2012). Success Factors for Deploying Cloud Computing. Communications of the ACM 55 (9), 62-68.

Garrison, G., Wade, J. B. \& Kim, S. (2015). The effects of IT capabilities and delivery model on cloud computing success and firm performance for cloud supported processes and operations. International Journal of Information Management 35, 377-393.

Ghemawat, S., Gobioff, H., Leung, S.-T. \& Inc., G. (2003). The Google File System. In: SOSP '03 Proceedings of the nineteenth ACM symposium on Operating systems principles, October 19-22, The Sagamore, Bolton Landing (Lake George), New York, USA.

Hodgkinson, I.R., Ravishankar, M.N. \& Aitken-Fischer, M. (2014). A resource-advantage perspective on the orchestration of ambidexterity, Service Industries Journal, 34(15),1234-1252.

Kern, T., Lacity, M. \& Willcocks, L. (2001). Application Service Provision, Englewood Cliffs, Prentice Hall.

Langley, A. (1999). Strategies for theorizing from process data. Academy of Management Review 24 (4), 691-710.

Levina, N. \& Ross, J. W. (2003). From the vendor's perspective: exploring the value proposition in information technology outsourcing. MIS Quarterly 27 (3), 331-364.

Lieberman, M. B. \& Asaba, S. (2006). Why Do Firms Imitate Each Other? Academy of Management Review 31 (2), 366-385.

Luo, Y., Sun, J. \& Wang, L. S. (2011). Emerging Economy Copycats: Capability, Environment, and Strategy. Academy of Management Perspectives 25 (2), 37-56.

Maritan, C. A. \& Peteraf, M. A. (2011). Invited Editorial: Building a Bridge Between Resource Acquisition and Resource Accumulation. Journal of Management 37 (5), 1374-1389.

Marston, S., Li, Z., Bandyopadhyay, S., Zhang, J. \& Ghalsasi, A. (2011). Cloud computing - The business perspective. Decision Support Systems 51, 176-189.

Mell, P. \& Grance, T. (2011). The NIST Denition of Cloud Computing. In: Computing Security Division, Information Technology Laboratory \& NIST (eds.). Gaithersburg: U.S. Department of Commerce and National Institute of Standards and Technology

Nevo, D. \& Kotlarsky, J. (2014). Primary vendor capabilities in a mediated outsourcing model: Can IT service providers leverage crowdsourcing? Decision Support Systems 65, 17-27.

Ong, J. (2012). Cloud atlas: A weather forecast on the Chinese cloud industry [Online]. TNW News. Available: 
http://thenextweb.com/asia/2012/12/01/cloud-atlas-the-state-of-the-chinese-cloud-industry/

[Accessed December 24th 2017].

Paquette, S., Jaeger, P. \& Wilson, S. (2010). Identifying the security risks associated with governmental use of cloud computing Government Information Quarterly 27 (3), 245 - 253.

Posen, H., Lee, J. \& Yi, S. (2013). The power of imperfect imitation. Strategic Management Journal 34, 149-164.

Ravichandran, T. \& Lertwongsatien, C. (2005). Effect of Information Systems Resources and Capabilities on Firm Performance: A Resource-Based Perspective. Journal of Management Information Systems / Spring , Vol. 21, No. 4, pp. 237-276 21 (4), 237-276.

Rothaermel, F. T. (2001). Complementary assets, strategic alliances, and the incumbent's advantage: an empirical study of industry and firm effects in the biopharmaceutical industry. Research Policy 30 (8), 1235-1251.

Sandeep, M.S. \& Ravishankar, M.N. (2015). Social innovations in outsourcing: An empirical investigation of impact sourcing companies in India. Journal of Strategic Information Systems, 24(4), 270-288.

Semadeni, M. \& Anderson, B. S. (2010). The follower's delimma: innovation and imitation in the professional serices industry. Academy of Management Journal 53 (5), 1175-1193.

Sirmon, D. G., Hitt, M. A., Ireland, R. D. \& Gilbert, B. A. (2011). Resource orchestration to create competitive advantage: breadth, depth, and life cycle effects. Journal of Management 37 (5), 1390-1412.

Teece, D. J. (1986). Profiting from technological innovation: Implications for integration, collaboration, licensing and public policy. Research Policy 15 (6), 285-305.

Teece, D. J. (2007). Explicating dynamic capabilities: the nature and microfoundations of (sustainable) enterprise performance. Strategic Management Journal 28, 1319-1350.

Teece, D. J. (2012). Dynamic Capabilities: Routines versus Entrepreneurial Action. Journal of Management Studies 49 (8), 1395-1401.

Teece, D. J. (2014). The foundations of enterprise performance: dynamic and ordinary capabilities in an (economic) theory of firms. The Academy of Management Perspectives 28 (4), 328-352.

Teece, D. J., Pisano, G. \& Shuen, A. (1997). Dynamic capabilties and strategic management. Strategic Management Journal 18 (7), 509-533.

Venters, W. \& Whitley, E. A. (2012). A critical review of cloud computing: researching desires and realities. Journal of Information Technology 27, 179-197.

Wade, M. \& Hulland, J. (2004). The resource-based view and information systems research: Review, Extension, and Suggestions for future research. MIS Quarterly 28 (1), 107-142.

Wernerfelt, B. (1984). A resource-based view of the firm. Strategic Management Journal 5, 171-180.

Wernerfelt, B. (2011). Invited Editorial: The Use of Resources in Resource Acquisition. Journal of Management 37 (5), 1369-1373.

Willcocks, L., Venters, W. \& Edgar, A. W. (2013). Cloud sourcing and innovation: slow traing coming? A composite research study. Strategic Outsourcing: An International Journal 6 (2), 184-202.

Willcocks, L., Venters, W. \& Whitley, E. A. (2014). Moving to the cloud corporation: How to face the challenges and harness the potential of cloud computing, Hampshire, Palgrave Macmillan.

Williamson, P. J. (2016). Building and Leveraging Dynamic Capabilities: Insights from Accelerated Innovation in China. Global Strategy Journal 6 (3), 197-210.

Winter, S. G. (2003). Understanding dynamic capabilities. Strategic Management Journal 24, 991-995. 
Yin, R. K. (2003). Case Study Research: Design and Methods, Third Edition, Califorinia, SAGE Publications.

Zollo, M. \& Winter, S. G. (2002). Deliberate learning and the evolution of dynamic capabilities Organisation Science 13 (3), 339-351.

\section{Appendices}

\section{Appendix A: Illustrative interview questions}

\section{Background}

- Could you tell us about your professional background?

- Could you briefly introduce your firm's cloud services?

\section{Cloud computing overview}

- What is your take on cloud computing?

- How and why is cloud computing different from other technologies?

- What are the unique selling points of your firm's cloud service offerings?

\section{Development of cloud services}

- What are the key aspects of your firm's cloud service development?

- How does your firm conduct innovation for service development/ generate new ideas?

- How does your firm sustain the continuity of the innovation efforts?

- Compared to leading vendors in the market, what are the new features/designs of your firm's cloud architecture?

- What programming languages do your firm's engineers adopt for implementation?

\section{Delivery of cloud services}

- How is the competition in the cloud computing market?

- What are the value propositions of your firm's cloud services?

- What are the clients' major expectations when using your firm's services?

- How does your firm gather/track clients' feedback?

- How does the reputation of Alibaba, the parent firm, affect your firm's service delivery?

- What are the clients' major concerns when adopt cloud computing?

- How does your firm build trust with clients?

- How does your firm meet clients' changing requirements?

- What support do you provide for first-time clients?

- Is top management support important for clients to adopt cloud services? Why? 


\section{Appendix B: List of interviewees}

\begin{tabular}{|c|c|}
\hline Data collection stages & Interviewee Number/Title \\
\hline Stage 1: Initial data collection & $\begin{array}{l}\text { - Industry insiders } \\
\text { 1) Business analyst, SAP } \\
\text { 2) Senior business analyst, SAP } \\
\text { 3) Director of cloud computing } \\
\text { 4) CTO of VMware } \\
\text { 5) Chief operation manager } \\
\text { 6) Project manager } \\
\text { 7) Software engineer } \\
\text { 8) Business analyst }\end{array}$ \\
\hline Stage 2: Site visit & $\begin{array}{l}\text { - Aliyun's employees } \\
\text { 9) Senior manager A } \\
\text { 10) Software engineer A } \\
\text { 11) Software engineer B } \\
\text { 12) Software engineer C } \\
\text { 13) Software engineer D } \\
\text { 14) Senior software engineer A } \\
\text { 15) Senior software engineer B } \\
\text { 16) Senior software engineer C } \\
\text { 17) Business analyst A } \\
\text { 18) Business analyst B } \\
\text { 19) Business analyst C } \\
\text { 20) Business analyst D } \\
\text { 21) Chief product manager } \\
\text { 22) Product manager A } \\
\text { 23) Product manager B } \\
\text { 24) Test manager A } \\
\text { 25) Test engineer A } \\
\text { 26) Test engineer B } \\
\text { 27) Test engineer C } \\
\text { 28) Cloud platform manager } \\
\text { 29) Research team leader } \\
\text { 30) Senior project manager } \\
\text { 31) Marketing manager A } \\
\text { 32) Marketing manager B } \\
\text { 33) Client support manager A } \\
\text { 34) Client support manager B } \\
\text { 35) Sales manager A } \\
\text { 36) Sales manager B } \\
\text { 39) Director of sales }\end{array}$ \\
\hline
\end{tabular}




\begin{tabular}{|l|l|}
\hline & 40) Director of marketing \\
& 41) Software engineer E \\
& 42) Software engineer F \\
& 43) Sales manager D \\
& 44) Marketing manager C \\
\hline Stage 3: Follow-up interviews & - Aliyun's employees \\
& 45) Test manger B \\
& 46) Test engineer D \\
& 47) Client support manager C \\
& 48) Senior manager B \\
\hline
\end{tabular}

\section{Appendix C: Other data sources}

\section{Aliyun documents}

- The design and implementation of Aliyun's Feitian Cloud Platform (2011): internal document

- An introduction of Aliyun's cloud architecture and IaaS offerings (2012): internal document

- Lingyun Journal, No. 1, February (2012): internally published journal

- Lingyun Journal, No.2, August (2012): internally published journal

- $\quad$ Lingyun Journal, No. 3, February (2013): internally published journal

- Lingyun Journal, No. 4, October (2014): internally published journal

- A review of Shanda Cloud Platform and IaaS services (2012): internal document

- The design and implementation of Shanda Cloud Platform (2011): internal document

- Shanda public cloud services (2012): internal document

- Aliyun's 3D rendering services (2013): internal classified document

- The history and current development of Alibaba's data synchronization (2013): internal classified document

- Aliyun's data security white paper (2012): white paper

- A guide of programming on Aliyun's Feitian Cloud Platform (2012): a book published by Publishing House of Electronics Industry)

- A lesson learned in Aliyun's cloud platform development (2014): internal document

\section{News articles}

- Aliyun hopes to acquire the technical capabilities of Google and Amazon (2012), (http://www.infoq.com/cn/news/2012/11/aliyun-interview-jinpei-tanghong, accessed on 27th of December, 2017)

- A conversation with Aliyun's CEO, Dr Jiang Wang (2012), (http://history.programmer.com.cn/9818/, accessed on 27th of December, 2017)

- Talking to CEO of Aliyun and VP of Alibaba Group, (2014), (http://www.csdn.net/article/1970-01-01/2820979, accessed on 27th of December, 2017)

- Aliyun first to achieve CSA STAR Gold Certification (2014), (http://www.bsigroup.com/en-GB/about-bsi/media-centre/press-releases/2014/January-2014/Aliyu n-first-to-achieve-CSA-STAR-Gold-Certification/, accessed on 27th of December, 2017)

- The path of Alibaba's technical development (2014), (http://www.tmtpost.com/499712.html, accessed on 27th of December, 2017) 
- Aliyun officially starts searching for partners (2014),

http://www.infoq.com/cn/news/2014/08/aliyun-partner, accessed on 27th of December, 2017)

- New record for world's biggest shopping day as Alibaba's shoppers spend \$9.3 billion in 24 hours (2014), https://www.techinasia.com/china-alibaba-singles-day-2014-spending-total, accessed on 27th of December, 2017)

\section{Articles on Aliyun webpages}

- Aliyun's compensation policies (2015),

(https://cn.aliyun.com/support/jpfw?spm=5176.8142029.419246.a111.N3ZfFY\#gold-tab-05, accessed on 27th of December, 2017)

- Aliyun's cloud-based solutions for distinct industries (2015),

(https://cn.aliyun.com/solution/all?spm=5176.7910928.321361.3.UNmNQL, accessed on 27th of December, 2017) 